\title{
Instance of Practical Engineering Application for Professional Education
}

\author{
BiYing Ren ${ }^{1, \mathrm{a}}$,LiQiang Zhu ${ }^{2, \mathrm{~b}}$ and Shihong Zhang ${ }^{3, \mathrm{c}}$ \\ ${ }^{1,2,3}$ Beijing Key Lab of Heating, Gas Supply, Ventilating and Air Conditioning Engineering, Beijing University of Civil \\ Engineering and Architecture, China \\ a147657638@qq.com, \\ byaonanguan@163.com, \\ ${ }^{\mathrm{c}}$ shihongzhang@bucea.edu.cn
}

\begin{abstract}
The experiment was divided into parts, one is about the concentration of exhaust gas when heating potteries, the other is about the content while heating without potter inside catalytic combustion furnace of natural gas. The potteries used for decorating by catalytic combustion furnace are more fine and glossy than the conventional ones. The catalytic combustion furnace of natural gas could be put on production of heating industries. The potteries heated by catalytic combustion furnace would be applied in decoration industries . Moreover, other researchers could learn in this method about the experiment's normal data model and how to use this catalytic furnace.
\end{abstract}

Keywords: pottery, carbon monoxide, carbon dioxide

\section{Introduction}

Originated from the United Kingdom, lean methane / air mixture in the combustion catalytic combustion is a new method. It was taken back to China by a tutor and gradually developed into what it is now. In theory, when the temperature in a furnace is about 1200 degrees Celsius, catalytic combustion of heterogeneous catalysis discharges a very small amount of co, nitrogen oxides and unburned hydrocarbons. [1]The purpose of this study is trying to generate heat with a suitable fuel (such as natural gas) and get the efficiency of nearly $100 \%$. During the experiment, the catalyst surface temperature is about 1200 to 1300 degrees Celsius, due to the capacity of the catalyst carrier, the practical temperature is usually around 1100 degrees Celsius. [1]In addition, though the total content of NOx increased continuously, the content is under $0.38 \mathrm{ppm}$, which almost can be ignored.[2]

Nowadays, $90 \%$ of the global industrial fuel comes from fossil fuels (oil, gas, coal), this situation will not change in the next 20 years.[3] Industrial furnace in China's total energy consumption accounts for a sizable proportion, which is about $20 \%$, but the average energy efficiency is only $35 \%$. The figure is less than half of which in Japan, the United States and other developed countries.[4]Therefore, it's of imperative to improve the fuel efficiency .The content of exhaust gas produced in catalytic combustion of natural gas provided by NIM, it can tell us that the contents of $\mathrm{CH} 4$ in exhaust gas was less than 5pm and the emissions of $\mathrm{NO} 2$ and $\mathrm{CO}$ were also closed to zero.[2]
During the process, the heating pottery was controlled manually, and after several experiments, I have gained the suitable temperature gradient for a mature heating technology. Under such circumstances, I also carried out a series of study in order to get a more powerful study of data.

\section{Experimental set-up}

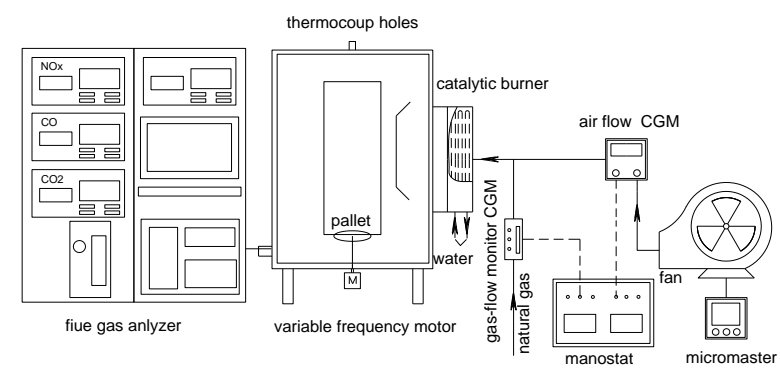

Figure1. Combustion system of catalytic combustion burner and flue gas analyzer

Figure. 1 presents the conventional diagram about system of catalytic combustion burner. The furnace body is connected to the catalytic burner, namely the catalytic combustion of burner. The catalytic combustion of burner installed two square catalytic honeycomb monolith every time .Every square honeycomb monoliths was $150 \mathrm{~mm}$ wide in sides of the square and $20 \mathrm{~mm}$ long, with square-shaped cells whose sectional area was $1 \mathrm{~mm} \times 1 \mathrm{~mm}$. The reaction region inside the catalysts was ended at about $10 \mathrm{~mm}$ from the monolith's entrance. The right part of burner connected with a section of pipe, which is a mixture of air and gas.

The control of air and gas respectively has their own independent reading device. The natural gas and air were regulated via GMS0050BRSN200000 natural gas meter and CMG400A080100000 air meter with $0 \sim 50 \mathrm{~L} / \mathrm{min}$ and $0 \sim 80 \mathrm{~m} 3 / \mathrm{h}$ of full-scale range respectively. The two meters were provided electric current. Exhaust gas went into the flue gas analyzer through hole on the left side of the burner. In order to improve radiant reflectance of the furnace cavity, high reflectivity of tin foil was taken in.

The natural gas was firstly let in (gas volume to 1 $\mathrm{L} / \mathrm{min}$ ), and the furnace starts running at the same time. After a few minutes, confirming the furnace is operating normally, the data were recorded every five minutes. The data were including temperature, concentration of carbon dioxide and carbon monoxide. Initially, the door 
of the heating Furnace was fully opened, in order to keep the temperature not too high. So when the temperature was relatively stable, the natural gas degree was adjusted into $5 \mathrm{~L} / \mathrm{min}$. The moment the temperature was relatively stable again, the door was shut gradually, so the temperature increased fifty or sixty degrees. The temperature was 366 degrees Celsius when the distance was $8 \mathrm{~cm}$ between door and doorjamb. The subsequent experiment process was the same taking the distance between door and doorjamb to $5 、 3 \mathrm{~cm}$, then the door was completely closed. And after the door's closing, the volumes of natural gas were adjusted into $6,7,8,9,10$ $\mathrm{L} / \mathrm{min}$, until the temperature rose to 800 degrees Celsius ,then heating pottery spent about 50 minutes until finishing.

For comparison with the heating potteries, the experiments of heating without potter inside catalytic combustion furnace of natural gas were also carried out. The main difference between the two was the impact of potteries' temperature, so the heating time was much less this time. And the data were recorded every five minutes as well, after combustion stabilized, the distance between door and doorjamb was turned into $8,5,3 \mathrm{~cm}$, and finally the door was shut down. After the door's closing, the volume of natural gas was changed into 6,7 , $8,9,10 \mathrm{~L} / \mathrm{min}$, until the temperature reached 800 degrees Celsius. Then the data were also calculated and analyzed.
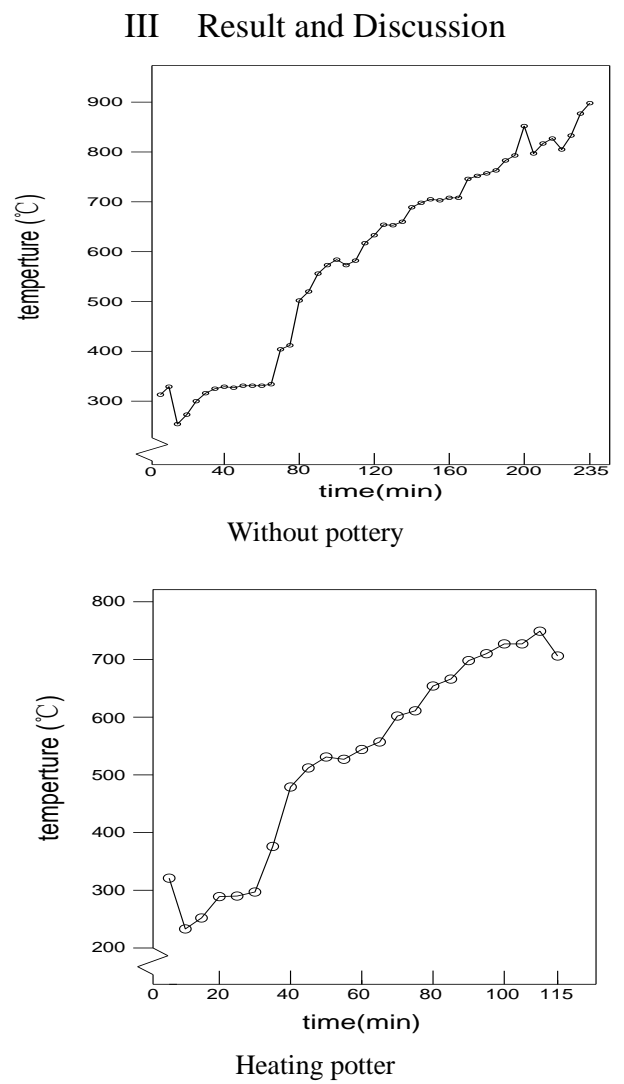

Figure 2. Temperature field inside catalytic combustion furnace
Heating potterObviously, the temperature inside the furnace gradually increased over time, and the door's closing is also an important factor. And when the distance between door and doorjamb was about 8 and 5, the temperature may increase by about 60 degrees Celsius. But due to the flow impact, the moment the door was fully closed, the temperature will decrease about 14 degrees Celsius. When the door closed and the temperature was stable, the amount of gas and air was adjusted, the temperature will also increase, but the increase is only about 20 degrees Celsius not as more as the previous ones. In particular, when the volume of natural gas was about $9 \mathrm{~L} / \mathrm{min}$ and $10 \mathrm{~L} / \mathrm{min}$, the Furnace was already 800 degrees Celsius or more, the furnace began to become very unstable, furnace black spots may also appear, making the Furnace unburnt. At that time, the accuracy of data were affected, especially the concentration of carbon monoxide.
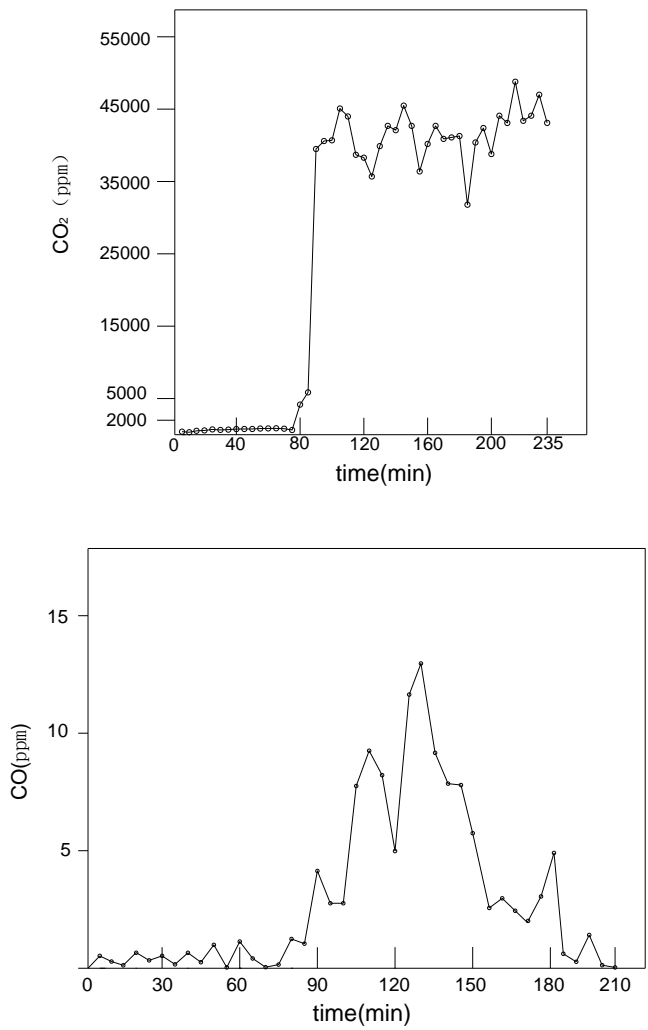

Heating potter 

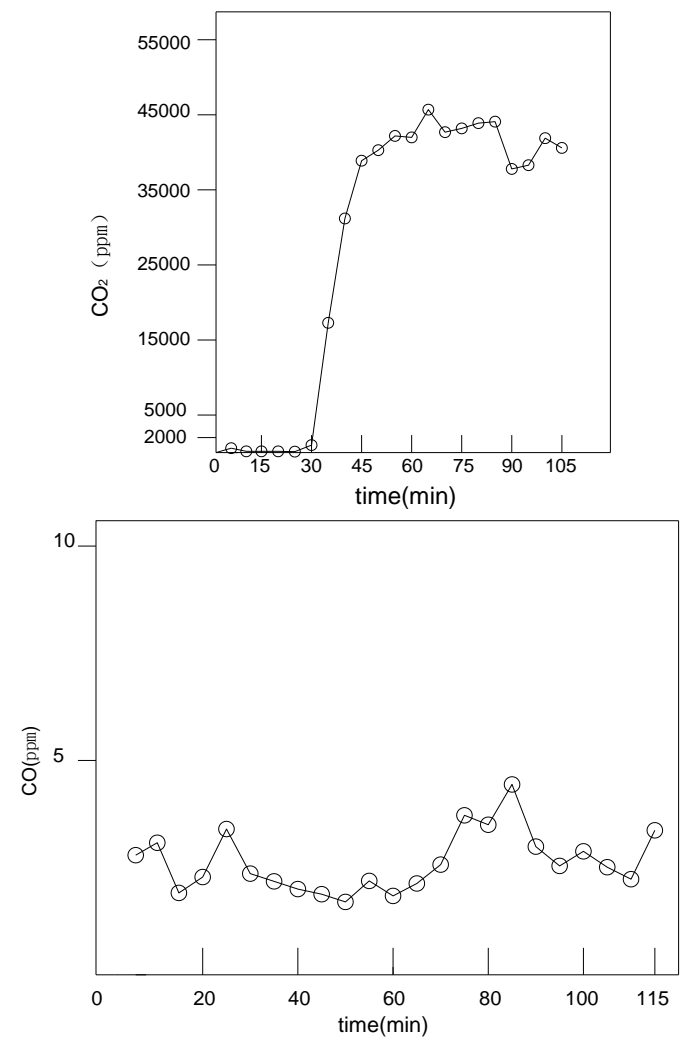

Without pottery

Figure3.Variation of Exhaust Gas Constituent

The graph clearly shows that as the temperature continues to rise, the concentration of carbon dioxide increased sharply after a while, reaching about $42,000 \mathrm{ppm}$ degrees Celsius. No matter what way was put into effect, the temperature did not fluctuate within a certain range, either air heating or heating potteries.And another result is that the trends and concentration of carbon dioxide in the furnace are barely affected, but air heating's fluctuations were smaller. Meanwhile, the concentration of carbon monoxide was affected by the pottery heating itself. In the course of air heating, the concentration of carbon monoxide was very low, basically between $2 \mathrm{ppm}$ and $3 \mathrm{ppm}$. Differently, in the process of heating potteries, the concentration was fairly low and stable initially, after about 45 minutes, the concentration of carbon monoxide has a very important fluctuation, up to $13.4 \mathrm{ppm}$. Therefore, the results show that heating porcelain will release carbon monoxide. The situation maintained about an hour,and then the carbon monoxide concentration began to come down, gradually restored to the initial level .

Another result shows that regardless of the heating method, the temperature in the one or two minutes could be higher than which in the five or six minutes. It's because the initial catalytic heating was flame combustion which produced much more heat. And then, the catalytic surface reacted, so the temperature began to decline.
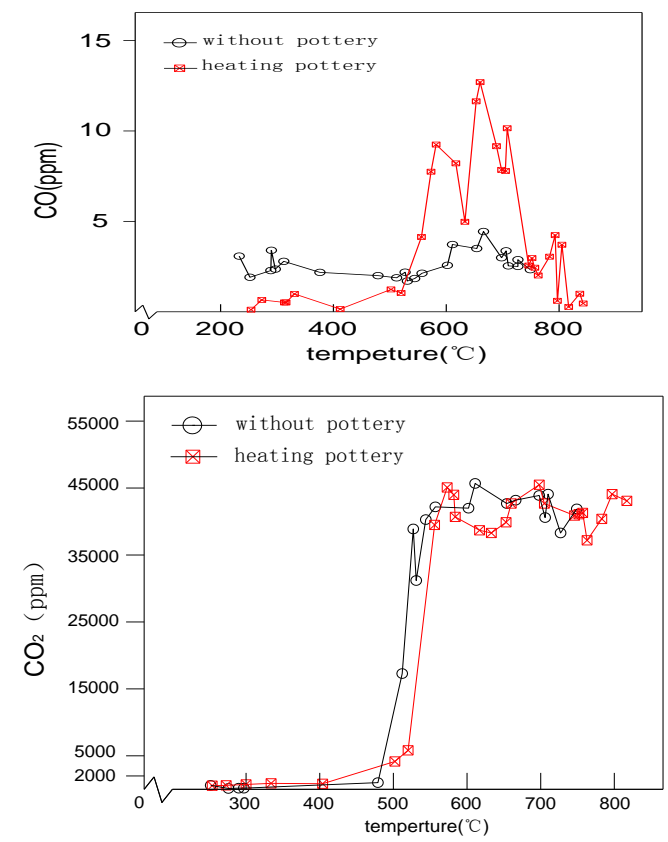

Figure4. concentration of carbon monoxide and carbon dioxide

The figure reveals that the tendency of concentration of carbon monoxide and carbon dioxide was similar to the gas concentration. And the concentration of carbon monoxide in the pottery process first increased, then reduced and gradually restored stability.

\section{Conclusion}

This experiment shows that whether it is empty or with pottery stuff, as long as the temperature reaches 800 degrees Celsius, the instability has still been existing inside catalytic combustion furnace of natural gas. This is also an important issue which needs further study in the future. In general, the whole process of heating potteries is adaptive for the catalytic combustion furnace and the experimental results are significant basis to the future study.

\section{Acknowledgments}

The project was sponsored by the Beijing Municipality Key Lab of Heating, Gas Supply, Ventilating and Air Conditioning Engineering; 2014 Funding Project (Building Environment and Facilities Engineering, Water supply and Sewerage engineering) and the Core Course of Heat Transfer.

\section{References}

[1]. Shi Hong Zhang, Dupont Valerie, Williams Alan, Rickett Gavin. Mechanisms and Applications of Catalytic Combustion of Natural Gas in the Presence of Sulphur Compounds. BJ: The Science Press. 2010, 56-88

[2]. X Y Wang, LQ Zhu, S H Zhang, Study on Low-carbon Catalytic Combustion Furnace of Natural Gas and the Application in Greenhouse, Advanced Materials Research Vol. 788 (2013) pp298-301

[3]. X Kong,Developmental Direction Of Energy Saving For Industrial Furnace In The New Century,2003.9

[4]. M S Jia ,Y X Feng,The Combustion Teehnology in Industrial Furnaeewith Low NO、Emission,524015 